\title{
Os aspectos Sociológicos na configuração imposta pelos enclaves.
}

The Sociological aspects in the configuration imposed by the enclaves.

Los aspectos sociológicos en la configuración impuesta por los enclaves.

Larissa Caroline Silva Jordão

Doutoranda, FAU UnB, Brasil arq.larissajordao@gmail.com

\section{Frederico Rosa Borges de Holanda} Professor Doutor, FAU UnB, Brasil. fredholanda44@gmail.com 


\section{RESUMO}

A proliferação de condomínios fechados desde a década de 1970 tem sido tema de grande relevância dentro do debate acadêmico. Após quase cinquenta anos do início deste tipo de empreendimento como forma de expansão urbana das cidades brasileiras é possível e necessário discutir os efeitos sociais desta configuração do espaço construído. Através de uma pesquisa documental dos processos de aprovação, relatórios de impactos de vizinhança de "condomínios horizontais fechados" e à luz de teorias morfológicas urbanas recentes, este artigo reflete sobre a configuração urbana destes elementos e suas implicações sociais, tem como foco as relações - arquitetura versus sociedade. Concorda-se que esta configuração dos espaços apresente efeitos que não são levados em consideração na atual forma de aprovação destes elementos, por acreditar-se de maneira equivocada que a arquitetura não defina e nem ao menos impacte o comportamento de uma determinada sociedade. As implicações sociais da configuração dos condomínios fechados são analisadas mediante os sistemas de barreiras (físicas, visuais, sociais e psicológicas) que eles constituem na relação com a cidade, particularmente quanto às grandes parcelas impermeáveis que se implantam.

PALAVRAS-CHAVE: Configuração urbana. Condomínios horizontais fechados. Análise urbana.

\section{RESUMEN}

La proliferación de condominios cerrados desde la década de 1970 ha sido tema de gran relevancia dentro del debate académico. Después de casi cincuenta años del inicio de este tipo de emprendimiento como forma de expansión urbana de las ciudades brasileñas es posible y necesario discutir los efectos sociales de esta configuración del espacio construido. A través de una investigación documental de los procesos de aprobación, informes de impactos de vecindad de "condominios horizontales cerrados" ya la luz de teorías morfológicas urbanas recientes, este artículo refleja sobre la configuración urbana de estos elementos y sus implicaciones sociales, tiene como foco las relaciones - arquitectura versus sociedad. Se acuerda que esta configuración de los espacios presenta efectos que no se tienen en cuenta en la forma actual de aprobación de estos elementos por creer equivocadamente que la arquitectura no defina ni al menos impacta el comportamiento de una determinada sociedad. Las implicaciones sociales de la configuración de los condominios cerrados son analizadas mediante los sistemas de barreras (físicas, visuales, sociales y psicológicas) que ellos constituyen en la relación con la ciudad, particularmente en cuanto a las grandes parcelas impermeables que se implantan.

PALABRAS CLAVE: Configuración urbana. Condominios horizontales cerrados. Análisis urbano.

\section{ABSTRACT}

The proliferation of closed condominiums since the 1970s has been a subject of great relevance within the academic debate. After almost fifty years of the beginning of this type of enterprise as a form of urban expansion of Brazilian cities it is possible and necessary to discuss the social effects of this configuration of the built space. Through a documentary survey of the approval processes, neighborhood impact reports of "horizontal closed condominiums" and in light of recent urban morphological theories, this article reflects on the urban configuration of these elements and their social implications, focusing on the relationships - architecture versus society. It is agreed that this configuration of spaces presents effects that are not taken into account in the current form of approval of these elements, because it is mistakenly believed that architecture does not define and at least does not impact the behavior of a given society. The social implications of the configuration of the closed condominiums are analyzed through the systems of barriers (physical, visual, social and psychological) that they constitute in relation to the city, particularly regarding the large impermeable parcels that are implanted.

KEYWORDS: Urban configuration. Condominiums closed. Urban analysis. 


\section{INTRODUÇÃO}

À luz das teorias morfológicas urbanas recentes (HOLANDA, 2013; KOHLSDORF; KOHLSDORF, 2017) assume-se neste artigo que a arquitetura deva ser entendida como "situação relacional" (KOHLSDORF; KOHLSDORF, 2017). A arquitetura ocasiona efeitos distintos nas pessoas: ela afeta nossos comportamentos, humor e relações, além de impactar o meio, seja natural ou construído, onde ela é inserida.

Estes efeitos, embora nem sempre programados e projetados previamente, derivam de escolhas conscientes, ou não, por parte dos produtores (pessoas, arquitetos, engenheiros, construtores etc.) de nossas cidades. Reflete -se assim, sobre as implicações sociais (efeitos) que a configuração urbana imposta pelos CHF's -- condomínios horizontais fechados - causam à sociedade.

Atualmente há muitas pesquisas sobre o ambiente construído e seus processos de urbanização, e sobre as consequências formais e físicas decorrentes das tomadas de decisão projetual nas cidades brasileiras. No entanto, esses vários olhares lançados sobre as cidades ainda se dão de forma segmentada, entre uma visão da cidade "social" e outra sobre a cidade "física" (HOLANDA, 2012).

Para o entendimento da configuração dos CHF's e suas implicações sociais, foi necessário tomar como embasamento para análise e compreensão as teorias morfológicas urbanas. Isto nos obriga a priori a compreender a arquitetura como um campo intermediado tanto pela "ciência quanto arte de fazer; tanto matéria quanto ideia; tanto produção quanto usufruto (ou consumo)". (KOHLSDORF; KOHLSDORF, 2017, p. 45).

Holanda e Medeiros (2012) afirmam que o espaço não é passivo, e dentro desta lógica enfatizam que existe uma relação entre pessoas e espaço. Ao definirem configuração urbana, grifam que aspectos quantificáveis e possíveis de serem medidos são apenas uma das maneiras de caracterizar a configuração urbana:

Taxas de ocupação, densidades edificadas, altura das edificações, usos, volumetria excepcional de alguns edifícios emblemáticos em contraste com a volumetria mais recorrente dos edifícios residenciais etc., fazem da cidade uma paisagem urbana variada. São aspectos das partes da configuração urbana. [HOLANDA; MEDEIROS, 2012, p. 42 - grifo nosso]

Para Holanda (2013) a compreensão do desempenho dos atributos dos elementos arquitetônicos é fundamental para o entendimento das expectativas que a sociedade tem com determinado ambiente construído. Desta forma, o autor relaciona oito aspectos: os funcionais, os bioclimáticos, os econômicos, os sociológicos, os topoceptivos, os afetivos, os simbólicos, e os estéticos - segundo Holanda (2013), é através deles que a arquitetura nos impacta. 
Sob este discurso manifesta-se aqui que todos os indivíduos (arquitetos, urbanistas, construtores, engenheiros, usuários, transeuntes, entre outros) interferem na configuração urbana das cidades, seja através de aspectos funcionais, bioclimáticos, econômicos e sociológicos, seja através dos aspectos topoceptivos, afetivos, simbólicos e estéticos.

Os Condomínios horizontais fechados apresentam sistemas de barreiras (físicas, visuais, sociais e psicológicas) que implicam mudanças nos processos relacionais entre arquitetura e sociedade.

\begin{abstract}
Abordar a arquitetura pelos aspectos sociológicos é focar as relações arquitetura $x$ sociedade especificamente quanto as relações entre configurações de edifícios, cidades e da paisagem natural entendida como arquitetura e as maneiras pelas quais as pessoas fazem o quê, como, onde, quando e com quem: como se estruturam encontros interpessoais, de forma mais ou menos planejada, mais ou menos casual, concentrados (ou não) no espaço ou no tempo (HOLANDA, 2014, p. 84 - grifo nosso).
\end{abstract}

Essa visão é fundamental para uma ampliação do entendimento sobre as cidades, uma vez que, na medida em que o tempo passa, a cidade evolui e não só suas características físicas mudam, mas suas atividades também alteram ao longo dos anos, assim como as relações e interações estabelecidas entre arquitetura e sociedade.

Por isso, a configuração imposta pelos condomínios horizontais fechados merece ser analisada à luz dessas novas teorias de morfologia urbana, e deve ser analisada mediantes seus aspectos (neste caso, os sociais), que atualmente não são levados em consideração na atual forma de aprovação destes assentamentos.

\title{
OBJETIVOS
}

Tem- se como objetivo geral deste artigo demonstrar que os processos de aprovação de projetos de Condomínios Horizontais fechados levam em consideração somente os impactos físicos e desconsideram os aspectos sociais. Pretende-se mostrar que esta forma de pensamento é errônea ao entender a arquitetura não interfira nas relações sociais.

\section{METODOLOGIA / MÉTODO DE ANÁLISE}

Trabalha-se com uma pesquisa de caráter quali-quantitativa, dada a necessidade de uma exploração acerca do material produzido até hoje, mas não descarta a importância da averiguação em campo. Uma vez que, acredita-se que a construção do caminho metodológico nas pesquisas urbanas, não pode deixar de levar em consideração quem são os sujeitos sociais que compõem a pesquisa.

Desta forma, inicialmente foi realizado um aprofundamento teórico sobre o tema e suas 

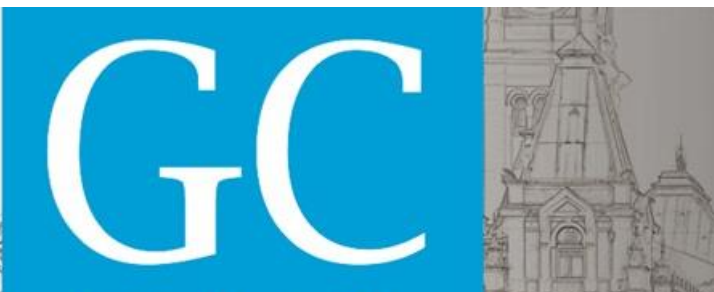

ISSN 2318-8472

v. $06, \mathrm{n} .44,2018$

Revista Nacional de

Gerenciamento de Cidades

respectivas correlações. Após a compreensão teórica, realizou-se um levantamento fotográfico da paisagem urbana consolidada pelos CHF's e um levantamento documental dos processos de aprovação dos CHF's que serviram de subsídio para uma interpolação dos dados e assim uma possível verificação da hipótese levantada.

\section{ARQUITETURA: OS CONDOMÍNIOS HORIZONTAIS FECHADOS}

Desde a década de 1970 o aumento dos condomínios passou a ser tema de grande relevância dentro dos debates acadêmicos. Após quase cinquenta anos do início deste tipo de empreendimento como forma de expansão urbana das cidades brasileiras é possível e necessário discorrer sobre os efeitos sociais dessa configuração do espaço construído.

Os CHF's - Condomínios horizontais fechados são semelhantes espacialmente aos loteamentos convencionais. São constituídos a partir de um arruamento, e suas quadras divididas em lotes particulares. Apesar dessas pequenas semelhanças com os loteamentos convencionais, eles não se confundem. No caso dos condomínios, eles são cercados e murados por elementos físicos e tecnológicos - como muros, grades, guaritas e câmeras de segurança. Impede-se a entrada e a passagem daqueles que não habitam o lugar.

Outra diferença que se apresenta atualmente é no âmbito jurídico: enquanto a maior parte dos condomínios horizontais fechados são aprovados pela lei 4.591 de 1964 ou por uma legislação pertinente, os loteamentos são aprovados pela lei de parcelamento do solo - lei federal 6.766 de 1979.

Os CHF's apresentam características físicas distintas em sua forma de implantação - casas sem muros/grades frontais, recuos frontais maiores e ajardinados (Figura 1), espaços coletivos com qualidade arquitetônica e paisagística (Figura 2), entre outras características.

Figura 1- Tipologia de casa dentro dos CHF's.

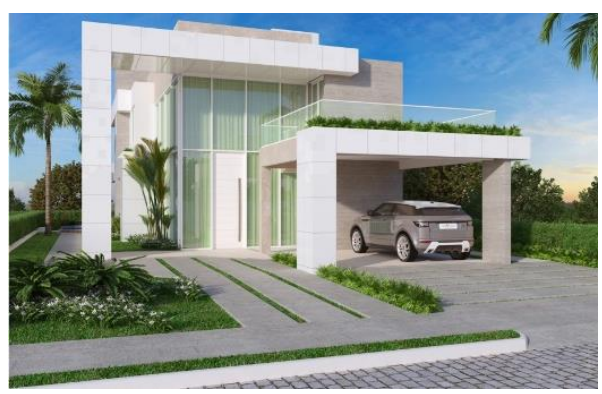

Fonte: Site Damha Urbanizadora.
Figura 2 - Área coletiva de um CHF's.

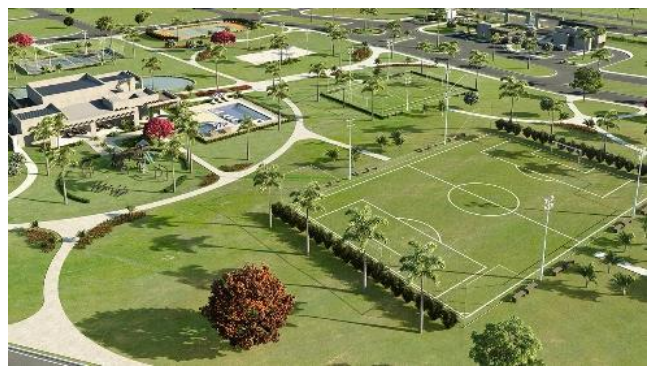

Fonte: Site Damha urbanizadora 

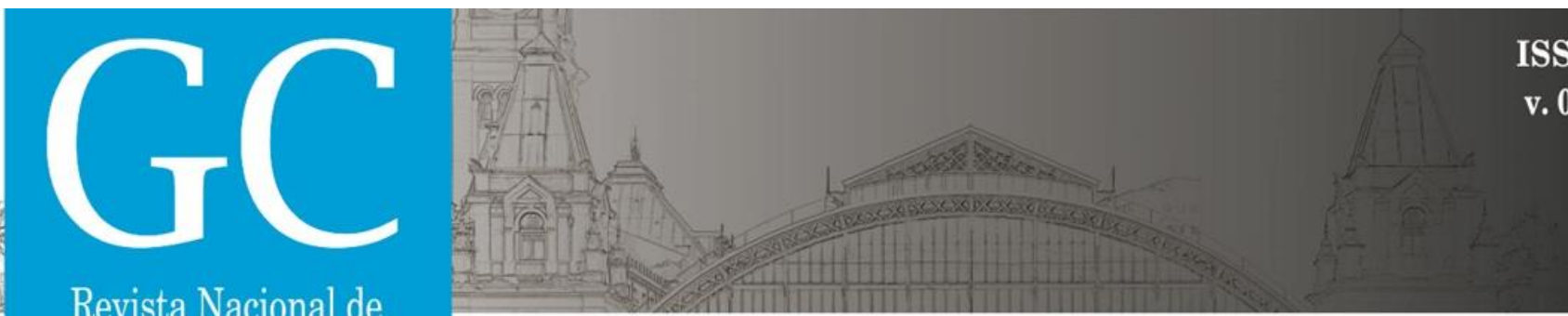

ISSN 2318-8472

Revista Nacional de

Gerenciamento de Cidades

Figura 3 - CHF's de Terrenos.

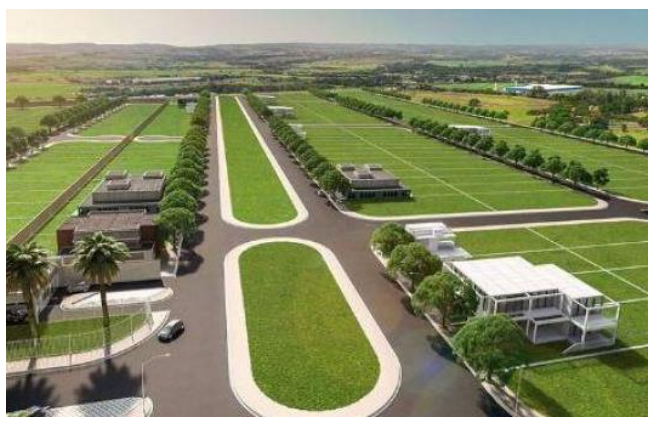

Fonte: Site Damha urbanizadora
Figura 4 - CHF's Casas prontas.

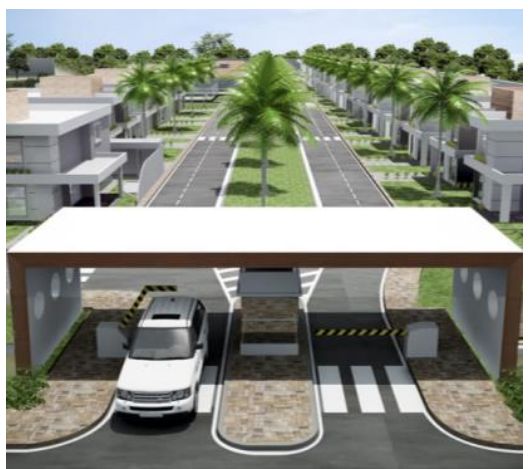

Fonte: Foxter

No Brasil, apesar de os CHF's - Condomínios horizontais fechados apresentarem características semelhantes entre si, percebemos em sua forma física alguns tipos distintos de CHF's. Blakely e Snyder (1997) e Grant (2003) indicam que podemos reconhecer pelo menos dois tipos de CHF's: 1- os Condomínios horizontais fechados suburbanos - que são amplos parcelamentos com no mínimo duzentos lotes, localizados em sua maioria na área rural ou periférica da cidade; 2- Condomínios horizontais fechados urbanos - que são de porte médio a pequenos, com até duzentos lotes, implantados em vazios urbanos dentro do tecido urbano já consolidado. Ambos podem ser constituídos por terrenos para a autoconstrução (Figura 3) ou já serem vendidos com a casa construída (Figura 4).

Com relação ao uso do solo também podemos observar algumas diferenças, enquanto alguns apresentam o uso misto de habitação, serviço e comércio, outros são apenas de uso habitacional, o que causam variações e diferenças na sua implantação, tamanho e impacto em seu entorno.

Também é possível reconhecer tipos sociais distintos de CHF's: 1 - Aqueles voltados à população de renda alta. Disponibilizam além da moradia, áreas de lazer completas (alguns inclusive com campos de golfe), sistema de segurança de última geração e fácil acesso às vias principais da cidade. 2 - Os voltados para a população de renda média. Oferecem moradias com áreas de lazer (piscinas, pistas de caminhada, áreas para pets etc.) e sistema de segurança mais modestos, e apesar de apresentarem um fácil acesso as vias de circulação, nem sempre possuem uma boa localização. 3 - E por fim, os CHF's que são direcionados para a população de baixa renda, que apresentam moradias padronizadas (minimiza os custos), contam com simples playground e área de lazer, e localizam-se em sua maioria em áreas periféricas.

Apesar das variações e distinções, ambos possuem alguns aspectos em comum como (i) a separação por classes de renda/social, (ii) a segregação por meio de aparatos de segurança, como muros e tecnologias, a (iii) homogeneização da paisagem e ruptura/fragmentação da 
estrutura urbana, a (iv) replicação de um determinado padrão de vida, e não menos importante, a (v) falta de permeabilidade e transparências à visão, a estrutura física da cidade e seu entorno imediato (Figura 5), em decorrência disto a negação ao espaço público - neste caso a rua.

Figura 5 - Falta de Permeabilidade - muros cegos dos CHF's.

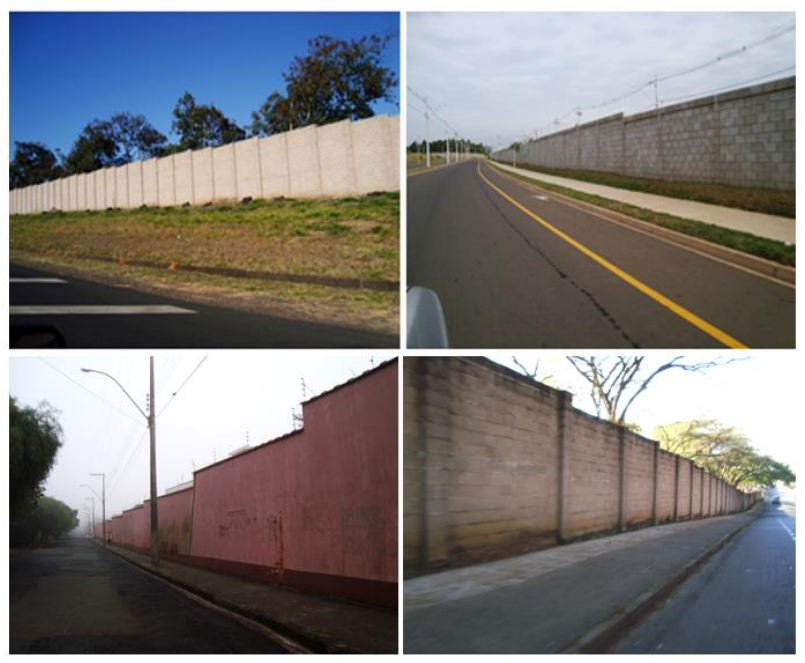

Fonte: Fotos arquivo pessoal - Cidade de São Carlos - SP.

Autores (SALGADO, 2000; CALDEIRA, 2000; SANTOS, 2002, entre outros) apontam que a continuidade da expansão urbana por meio de Condomínios Horizontais fechados pode trazer problemas como 1- o aumento das distâncias e dos deslocamentos pendulares, 2 - a ampliação da frota e do uso de transportes particulares, como carros e motos, 3 - o desenvolvimento de cidades dispersas com baixa taxa de densidade, 4 - o encarecimento da infraestrutura, 5 -o não favorecimento da diversidade social, espacial e a mistura de usos, 6 - o aumento do impacto ambiental, além do 7 - favorecimento ao aumento da segregação e da violência.

Alerta-se aqui para uma outra problemática, de que essa decisão a priori individual de morar em CHF's pode gerar resultados coletivos sociais não-intencionais, mas mesmo assim impactantes modeladoras da configuração do espaço construído. Como mudanças nas relações entre as configurações da arquitetura (aqui os CHF's) e sociedade (pessoas que ali frequentam, interna ou externamente).

Percebe-se que nos últimos anos, brasileiros tomaram a decisão de buscar moradia dentro de CHF's, e por isso vemos um aumento na oferta e no tamanho dos condomínios horizontais fechados. Portanto, devemos estar atentos ao impacto coletivo dessa configuração dos espaços construídos, que apresenta efeitos sociais que não são levados em consideração na 
atual forma de aprovação destes assentamentos, por acreditar-se de forma equivocada que a arquitetura não defina e nem ao menos impacte o comportamento de uma determinada sociedade.

\section{SOCIEDADE: A POPULAÇÃO DOS CONDOMÍNIOS HORIZONTAIS FECHADOS}

A década de 1970 também é marcada pela transposição do Brasil rural para o Brasil Urbano e o ápice da ditadura militar, período em que passamos a experienciar uma sociedade que busca entre tantas outras realizações, uma nova forma de vida.

Desde então, segundo Dunker (2015), passamos a vivenciar um discurso pautado em patologias narcisistas e autor-referenciados. Que enfatizam a necessidade de proteção contra o "outro" e o "desconhecido" (seja de gênero, cor, renda, classe ou etnia).

Percebe-se neste momento uma sociedade concentrada em núcleos urbanos, agora mais densos e por isso mais diversos e heterogêneos. Essa diversidade, e o medo do desconhecido, origina um sentimento retórico de que o outro seja perigoso e ameaçador e que a solução para este problema seja a negação de tudo que para ele seja diferente.

Dessa forma, temos uma sociedade pautada em uma narrativa do medo e do sofrimento (DUNKER, 2015), de que o mal está associado ao que vem de fora (seja estrangeiro, diferente etc.), e como uma das possíveis soluções de apartação criam-se os muros - elemento físico, mas que aqui compreende uma conotação simbólica de separação e organização entre o que/quem fica dentro e o que/quem está fora.

Os primeiros CHF's se apresentavam como um grande modelo de vida e um ideal de consumo. Traziam o sentimento de segurança e ordem como característica principal, e assim a ideia de que através dessa nova forma de viver - os seus problemas terminariam (Figura 6). 

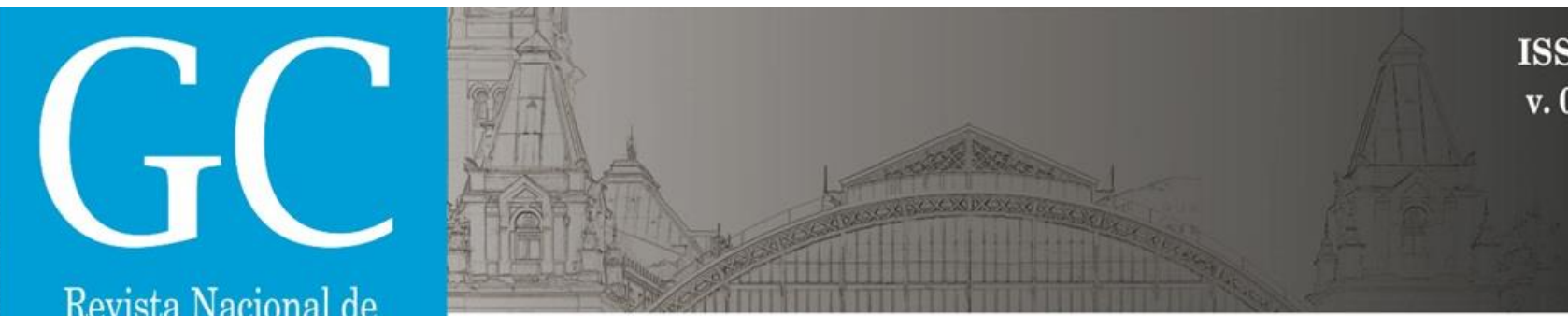

ISSN 2318-8472

v. 06, n. 44, 2018

Revista Nacional de

Gerenciamento de Cidades

National Journal of Cities Management

Figura 6 - Propagandas vinculadas aos CHF's.
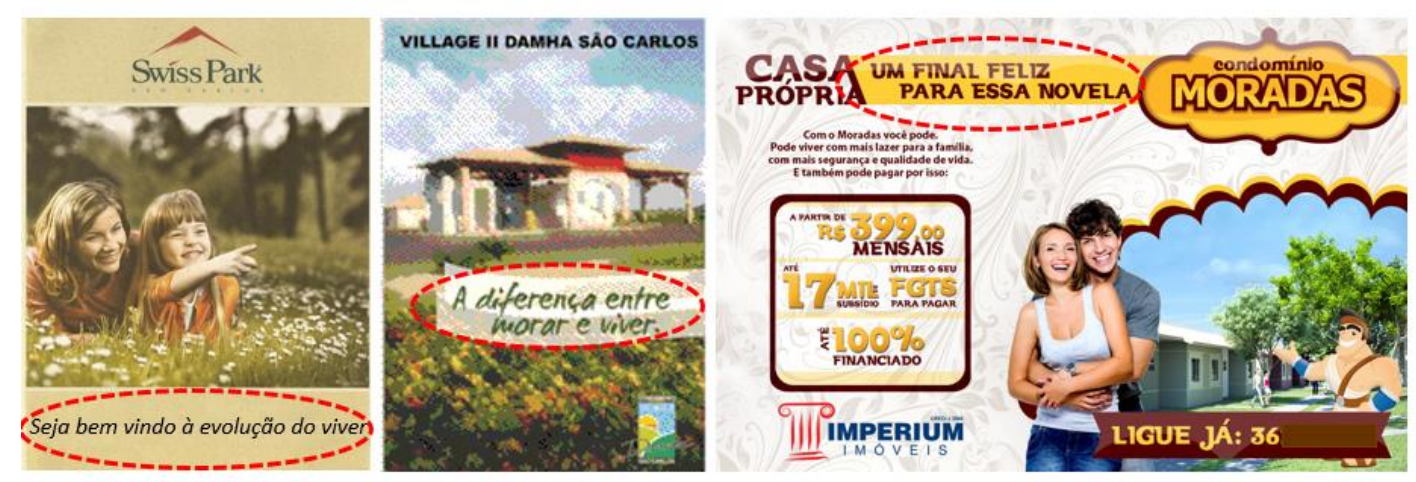

Fonte: Panfletos de arquivo pessoal - Coletados na cidade de São Carlos - SP.

Org.: Autor.

A sociedade passa a enxergar nos CHF's mais do que uma experiência espacial distinta, mas a possibilidade de mudanças sociais - mesmo que intramuros e por curtos períodos de tempo, por transformar através dos muros o "lado de fora" em invisível e indiferente.

Os moradores dos CHF's passam a ter uma dinâmica de vida distinta dos moradores de loteamentos convencionais. Devido aos muros, não existe nenhum tipo de interação com o entorno imediato, e a distância da maioria dos CHF's aos centros urbanos faz com que as pessoas recorram aos transportes individuais e de uso particular - evita-se assim percursos a pé (potenciais à apreensão, compreensão e dinâmica social), além de preferirem as vias rápidas para percorrem essas grandes distantes - ocasiona-se uma mudança na forma de apreensão visual devido ao aumento da velocidade.

Figura 7 - Corredor de um Shopping, ao fundo simulacro de uma paisagem urbana.

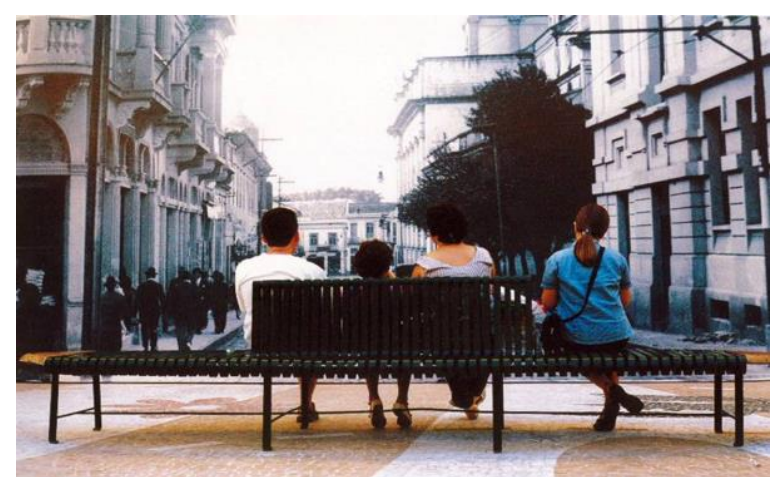

Fonte: Foto de arquivo pessoal - Shopping na cidade de São Paulo - SP. 
Outra característica dessa sociedade é a preferência por lugares mediados por barreiras físicas, visuais, sociais e psicológicas, semelhantes ao CHF's, para a diversão, entretenimento, compras etc., como os shoppings centers, malls, parques temáticos, e clubes (Figura 7). Evita-se a permanência em espaços públicos, principalmente os abertos que promovam a diversidade e 0 encontro.

Dentro dos CHF's as pessoas têm uma maior sensação de controle daquilo que extramuros não nos é permitido: como planejar o encontro interpessoal e selecionar quem e qual horário outras pessoas poderão "bater" em suas portas, sempre resguardados pela triagem de suas portarias, câmeras e síndicos.

Isso faz com que a sociedade brasileira passe a ser percebida pelos produtores urbanos como uma fonte de renda potencial. Atraídos por um discurso que enaltece as suas próprias narrativas, a sociedade passa a contribuir integralmente a uma lógica mercadológica, que deixa em segundo plano questões sociais reais que o espaço (re) produz.

Essas questões enaltecem a necessidade de que as implicações sociais da configuração dos condomínios fechados sejam analisadas mediante os sistemas de barreiras (físicas, visuais, sociais e psicológicas) que eles constituem na relação com a cidade, particularmente quanto às grandes parcelas impermeáveis que se implantam.

\section{PROCESSO DE APROVAÇÃO E SUAS IMPLICAÇÕES}

O IBGE com base nos dados coletados anualmente (Figura 8), apresenta a quantidade de pessoas que moram em casas de condomínios. Percebemos que essa decisão (a priori individual) em morar em casas de vila ou condomínios não tem sido um caso restrito a algumas pessoas. Nota-se que em 2010 o censo já acusava que cerca de 1.024 .743 pessoas moravam em condomínios ou vilas.

Figura 8 - Tipo de Domicílio.

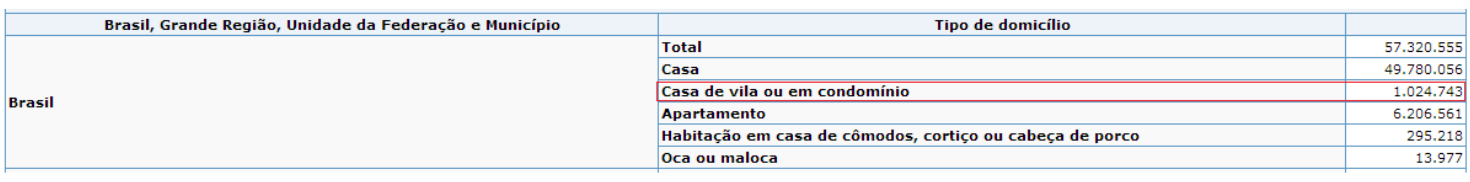

Fonte: Instituto de Brasileiro de Geografia e Estatísticas, 2010.

Essas pessoas passam a buscar os CHF's como uma nova forma de viver, algumas por segurança, outras por "status", ou em busca de melhor qualidade de vida, entre outros motivos (JORDÃO, 2014). Dessa forma, essa decisão deixa de ser por parte de um único indivíduo para ser tomada por grupos de pessoas, de forma coletivizada (Figura 9), 

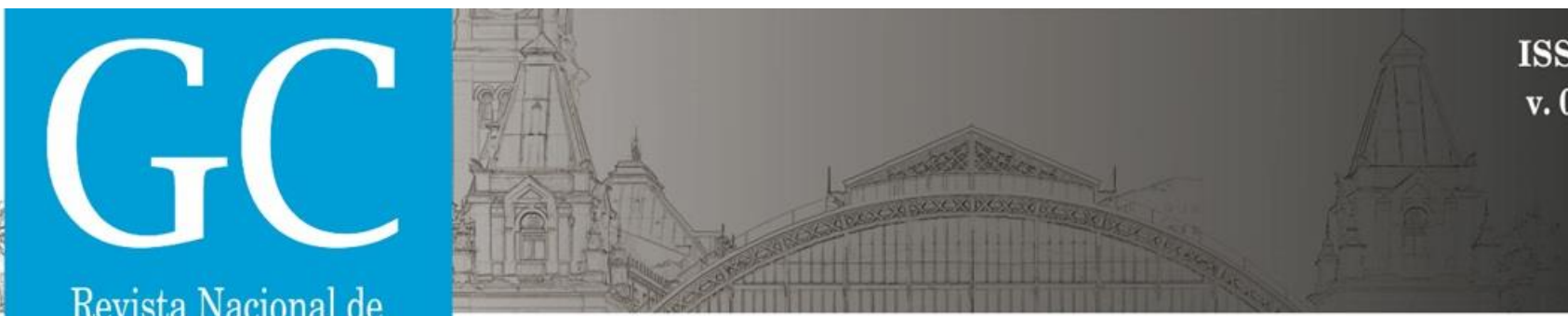

ISSN 2318-8472

v. 06, n. 44, 2018

Revista Nacional de

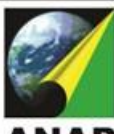

Gerenciamento de Cidades

National Journal of Cities Managemen

maximizando as possíveis mudanças e efeitos dessa configuração ao espaço construído.

Figura 9 - Área de concentração de CHF's.

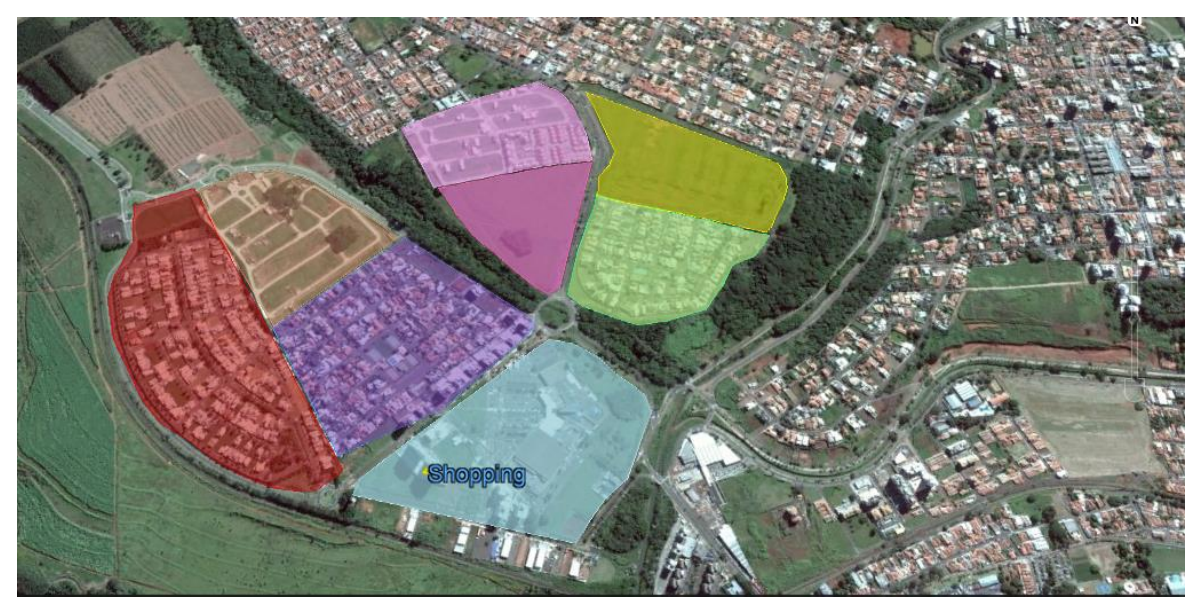

Fonte: Google Earth - com adaptações.

Podemos observar que a decisão individual em primeira instância não é causadora de impactos maiores e perceptíveis ao espaço construído. Entretanto ao ser coletivizada e partilhada por grande parte da população e construtores percebe-se grandes impactos físicos na malha da cidade (Figura 9). Contudo, questiona-se também sobre outro efeito dessa configuração, os de ordem social que apesar de serem percebidos na cidade com o passar do tempo e do aumento de sua escala, não são levados em consideração na hora de projetar, aprovar e implantar os CHF's.

Este questionamento se dá com base em que, apesar da escala desses empreendimentos que buscam o máximo aproveitamento de suas glebas e assim a maior quantidade possível de lotes (Figura 10 - são 929 unidades aprovadas intramuros), eles são inseridos na maior parte das cidades brasileiras sem levar em discussão os seus efeitos sociais no espaço construído. 


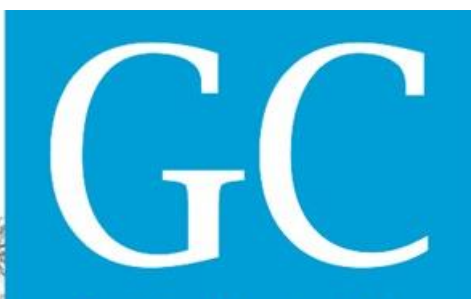

Revista Nacional de

ISSN 2318-8472

v. $06, \mathrm{n} .44,2018$

Gerenciamento de Cidades

National Journal of Cities Manayement

Figura 10 - Projeto de aprovação de CHF's

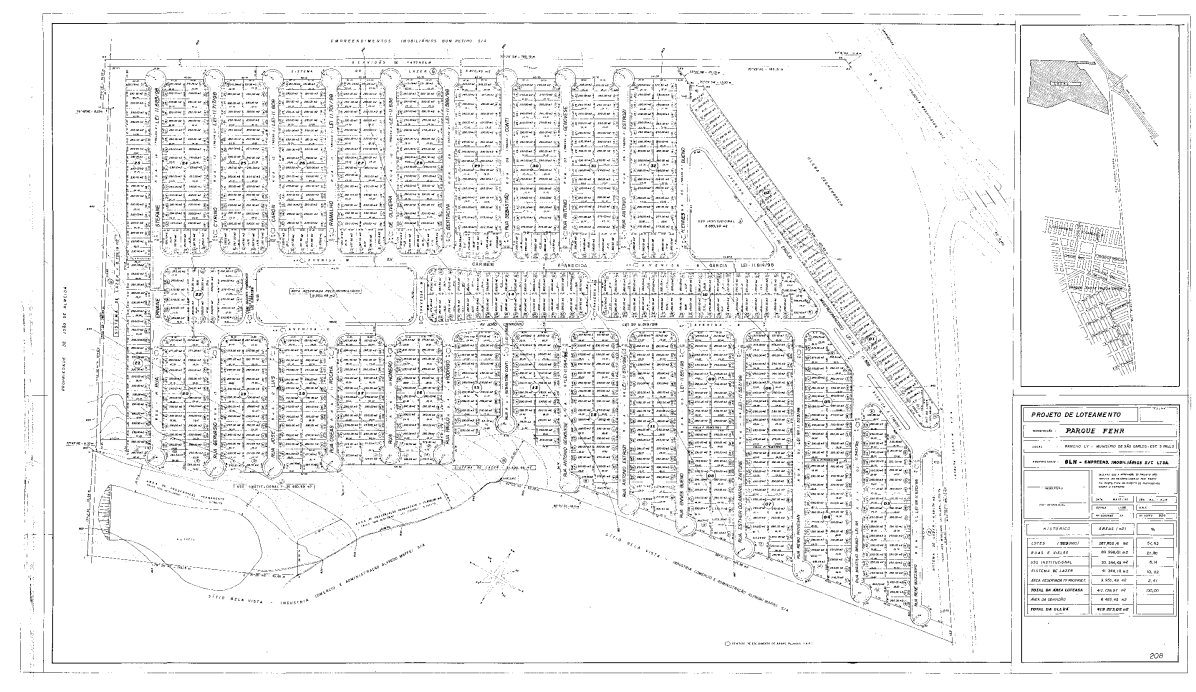

Fonte: Prefeitura Municipal de São Carlos.

Para a aprovação de alguns empreendimentos, o Estatuto da Cidade sugere que os municípios utilizem o EIV - Estudo de Impacto de Vizinhança, que tem como ideal prever e minimizar impactos negativos (adensamento das vias adjacentes, incômodo com execução da obras, capacidade dos equipamentos ao redor, interferências na paisagem entre outros) e potencializar os impactos positivos (revitalização da área, adensamento apropriado, contribuir para cumprir o valor social de uma área, entre outros), de forma a propiciar maior e melhor consequências à qualidade de vida não só daqueles que residirão e usufruirão do espaço, mas também daqueles que de forma direta ou indireta serão por ele afetado.

No entanto, de acordo com a seção XII, do artigo 36, da lei no 10.257/2001 - o Estatuto da Cidade, quem definirá quais os empreendimentos que deverão elaborar um estudo prévio de impacto de vizinhança é o próprio poder público municipal:

Art. 36. Lei municipal definirá os empreendimentos e atividades privados ou públicos em área urbana que dependerão de elaboração de estudo prévio de impacto de vizinhança (EIV) para obter as licenças ou autorizações de construção, ampliação ou funcionamento a cargo do Poder Público municipal. (Lei no 10.257/2001. Grifo nosso).

Ao analisar alguns exemplares de projetos de aprovação de Condomínios horizontais fechados, percebe-se que apesar de ser notável que os impactos não são somente de ordem espacial, os projetos e os estudos de impacto de vizinha, quando elaborados, se detém somente em aspectos quantitativos físicos: como energia, densidade, ocupação, vias adjacentes - fluxos, topografia, mata ciliar, entre outros (Figura 11). 


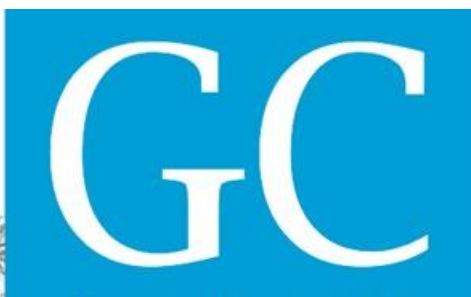

Revista Nacional de

ISSN 2318-8472

v. $06, \mathrm{n} .44,2018$

Gerenciamento de Cidades

National Journal of Cities Management

Figura 11 - Projetos de aprovação e impactos analisados.

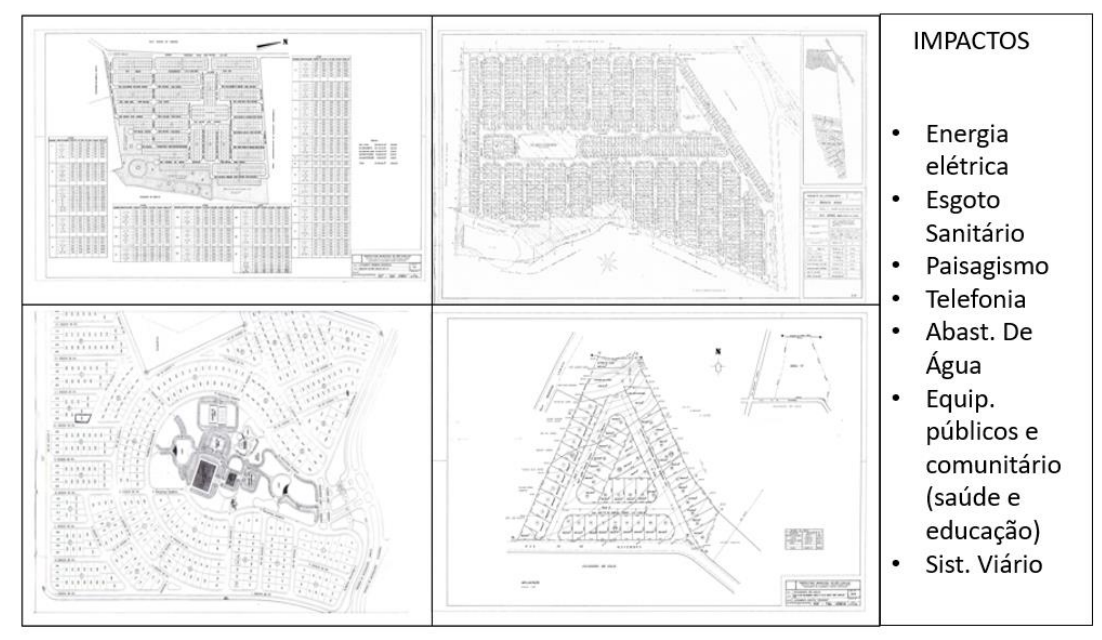

Fonte: Prefeitura Municipal de São Carlos, c/ adaptações.

Podemos acusar que os condomínios horizontais fechados apesar de serem implantados somente com base em análises espaciais, eles também interferem na configuração do espaço construído de outras formas, muitas vezes não planejadas - como no aspecto social:

1. Devido sua localização, na maioria das vezes distante dos centros - ocasiona fluxos a partir de automóveis particulares, acarretando dinâmicas distintas e possível falta de processos sociais com seu entorno - e assim uma nova forma de percepção da paisagem. Uma vez em que os processos de locomoção são realizados de carro, o que acarreta uma nova forma de sentir, perceber e ver a paisagem que se concretiza;

2. processos sociais precários e superficiais, como as que ocorrem nas reuniões obrigatórias nas áreas comuns ao $\mathrm{CHF}^{\prime}$;

3. pouca e algumas vezes inexistente relação social com a área externa ao CHF's devido às barreiras físicas;

4. falta de percursos a pé (passeios e permanência - propícios à interação social) devido à localização próxima a vias de circulação rápida e a facilidade de locomoção por automóveis particulares;

5. preferência por lugares similares aos CHF's, como os shoppings e malls, controlados a todo momento e que regulam as interações sociais permitidas no espaço;

6. falta de permeabilidade visual decorrente dos muros e barreiras cegas que "protegem" os CHF's e favorece a falta de vitalidade nas ruas ao seu redor e assim 


\section{Revista Nacional de}

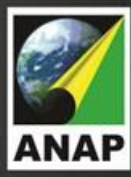

compromete a possibilidade de elos afetivos com o lugar e de relações sociais com o espaço construído e com as pessoas;

7. criação de elementos homogêneos e sem identidade, que se repetem de cidade em cidade - dificultando a criação de elementos simbólicos que contribuam para a compreensão espacial urbana da sociedade e as relações sociais; entre tantos outros.

Holanda (2013) discorre sobre como a arquitetura acarreta uma série de efeitos nas cidades e nas pessoas, entre os vários aspectos citados, a dimensão sociológica contribui diretamente para a compreensão do fenômeno e assim para criação de qualidades que podem colaborar para os elos afetivos entre o meio e as pessoas, base segundo o autor para que haja urbanidade.

Figura 12 - Ciclo Sociedade x CHF's.

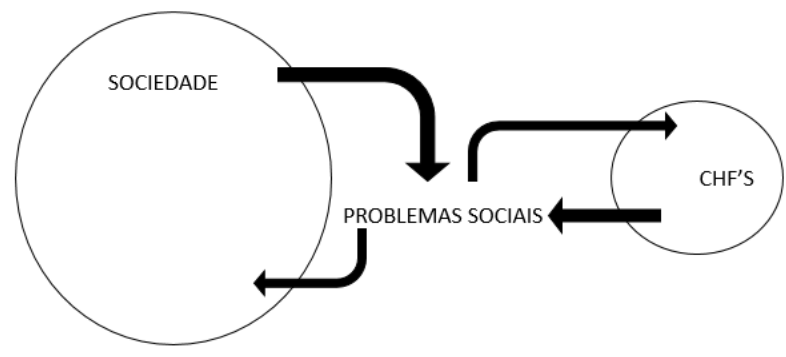

Fonte: arquivo próprio.

O autor afirma que "essas dimensões socioespaciais - da arquitetura e da sociedade - têm profundas implicações quanto a estruturações sociais, simetrias ou assimetrias sociais, estruturas de poder" (HOLANDA, 2013, p. 84). Percebe-se dessa forma, que as transformações acusadas desde 1970 - na sociedade e na arquitetura, criam um ciclo, onde os problemas sociais demandam soluções espaciais, que por sua vez, irão ocasionar outros problemas sociais (Figura 12).

\section{CONCLUSÃO}

Fica evidente, que apesar do eminente esforço de mimese por parte dos CHF's para se assemelharem aos espaços públicos (estes contemplam uma série de aspectos), os CHF's ainda desconsideram vários aspectos - principalmente durante seu processo de elaboração, aprovação e implantação, onde são avaliados somente aspectos quantificáveis e físicos.

A sociedade ao buscar os CHF's como forma de enaltecer ou resolver seus problemas sociais 
acabam por maximizar outros: os decorrentes da falta de permeabilidade e transparências à visão. Criam - se lugares definidos por amplas barreiras físicas e psicológicas e os seus efeitos sociais passam a ser percebidos ao longo do tempo e do espaço:

1 - Enrijecimento da pirâmide social e das estruturas de poder,

2- Distinção e separação da sociedade por muros,

3- Separação por grupos homogêneos,

4 - Falta de contato/interação social com diferentes,

5 - Intolerância ao que não se adeque ao seu meio,

6 - Diminui a noção de engajamento cívico, uma vez que os problemas sociais são minimizados intramuros, entre outros.

Apesar de muitas destas questões serem evidentes em nossa sociedade atualmente, percebese que ainda se faz presente uma visão segmentada entre arquitetura e sociedade, entre o que é físico e o social. No caso da aprovação de projetos de CHF's leva-se em consideração os impactos físicos e são desconsiderados os aspectos sociais. Acredita-se de forma errônea que a arquitetura, neste caso dos CHF's, não interfira nas relações sociais.

Este posicionamento deflagra um processo cíclico (Figura 12), que para ser solucionado demanda uma visão integrada perante essas questões. A arquitetura precisa ser compreendida de forma completa e interpretada não somente através de seus elementos visíveis e quantificáveis, mas também através dos aspectos que a ela ficam intrínsecos, como os sociológicos.

Mediante o tamanho e o impacto social que esta configuração dos CHF's ocasiona ao ambiente construído, visto a quantidade de pessoas que optam atualmente por este tipo de moradia, é necessário que os aspectos sociológicos sejam incorporados à forma de análise para a aprovação de um empreendimento deste porte. E assim, findarmos com a visão separatista de que as questões espaciais devam ser analisadas de forma independente das questões sociais. 


\section{REFERÊNCIAS BIBLIOGRÁFICAS}

AUGÉ, Marc. Não-Lugares: Introdução a uma antropologia da supermodernidade. São Paulo: Ed. Papirus, 1994.

BAUMAM. Z.. Comunidade: a busca por segurança no mundo atual. Trad. de Plínio Dentzien. Rio de Janeiro: Jorge Zahar, 2003.

BLAKELY, Edward J. SNYDER, Mary Gail. Fortress America: Gated Communities in the United States. Washington e Cambridge: Brookings Institution Press e Lincoln Institute of Land Policy, 1997.

BRASIL. Lei no 10.257 de 2001. Regulamenta os arts. 182 e 183 da Constituição Federal, estabelece diretrizes gerais da política urbana e dá outras providências. Diário Oficial [da] república Federativa do Brasil, Poder executivo, Brasília, DF, 10 de julho de 2001.

BRASIL. Lei no 4591 de 16 de dezembro de 1964. Dispõe sobre o condomínio em edificações e as incorporações imobiliárias. Diário Oficial [da] república Federativa do Brasil, Poder executivo, Brasília, DF, 16 de dezembro de 1964.

BRASIL. Lei no 6766 de 19 de dezembro de 1979. Dispõe sobre o Parcelamento do Solo Urbano e dá outras Providências. Diário Oficial [da] república Federativa do Brasil, Poder executivo, Brasília, DF, 19 de dezembro de 1979.

CALDEIRA, T. P. do R.. Cidade de muros: crime, segregação e cidadania em São Paulo. São Paulo: Edusp. 2000.

DUNKER, Christian. Mal-estar, sofrimento e sintoma. A psicopatologia do brasil entre muros no Brasil. Brasil: Ed. Boitempo, 2015.

GRANT, Jill. Planning responses to gated communities in Canada. In.: Conference Gated Communities: Building Social Division or Safer Communities? Glasgow: University of Glasgow. Setembro, 18-19, 2003.

HOLANDA, F.. O espaço de exceção. Brasília: Ed.UnB, 2010.

HOLANDA, F.; MEDEIROS, V.. Ordem \& Desordem em Brasília \& Chandigarh. In: HOLANDA, F.. Ordem \& Desordem: Arquitetura \&Vida social. Brasília: Ed. FRBH, 2012. Cap.01, p.17-46.

HOLANDA. F.. 10 mandamentos da Arquitetura. Brasília: FRBH, 2013

INSTITUTO BRASILEIRO DE GEOGRAFIA E ESTATÍSTICA. Censo populacional 2010. Disponível em http://www.ibge.gov.br, acessado em outubro de 2017.

JORDÃO, L.. [Sub]urbanização: a expansão urbana de São Carlos por meio dos condomínios. 2014. 185 f. Dissertação (Mestrado) - Faculdade de Arquitetura e Urbanismo. Universidade de Brasília, Brasília, 2014.

LYNCH, Kevin. The image of the city. Cambridge: The M.I.T. Press, 1960.

SALGADO, Elizabeth. O Loteamento residencial fechado no quadro das transformações da metrópole de São Paulo. Dissertação de Mestrado. Faculdade de arquitetura e urbanismo - Universidade de São Paulo. São Paulo: 2000.

SANTOS, Denise Mônaco dos. Atrás dos muros: unidades habitacionais em condomínios horizontais fechados. Dissertação de Mestrado. São Carlos, 2002. 